\title{
Protein kinase CK2 in development and differentiation (Review)
}

\author{
CLAUDIA GÖTZ and MATHIAS MONTENARH \\ Department of Medical Biochemistry and Molecular Biology, Saarland University, D-66424 Homburg, Germany
}

Received October 25, 2016; Accepted December 6, 2016

DOI: $10.3892 /$ br.2016.829

\begin{abstract}
Among the human kinomes, protein kinase CK2 (formerly termed casein kinase II) is considered to be essential, as it is implicated in the regulation of various cellular processes. Experiments with pharmacological inhibitors of the kinase activity of $\mathrm{CK} 2$ provide evidence that CK2 is essential for development and differentiation. Therefore, the present review addresses the role of CK2 during embryogenesis, neuronal, adipogenic, osteogenic and myogenic differentiation in established model cell lines, and in embryonic, neural and mesenchymal stem cells. CK2 kinase activity appears to be essential in the early stages of differentiation, as CK2 inhibition at early time points generally prevents differentiation. In addition, the present review reports on target proteins of CK2 in embryogenesis and differentiation.
\end{abstract}

\section{Contents}

1. Introduction

2. CK2 during embryogenesis

3. CK2 and neuronal differentiation

4. CK2 and adipogenic differentiation

5. CK2 and myogenic differentiation

6. CK2 and osteogenic differentiation

7. $\mathrm{CK} 2$ in hematopoietic differentiation

8. Conclusion

\section{Introduction}

Protein phosphorylation and dephosphorylation are important post-translational modifications in cellular regulation. According to Manning et al (1) the human kinome consists of 518 protein kinases, which catalyze the transfer of the terminal

Correspondence to: Professor Mathias Montenarh or Professor Claudia Götz, Department of Medical Biochemistry and Molecular Biology, Saarland University, Building 44, D-66424 Homburg, Germany

E-mail: mathias.montenarh@uks.eu

E-mail: claudia.goetz@uks.eu

Key words: embryogenesis, adult stem cells, phosphorylation, CK2 substrates phosphate group of a nucleotide to a substrate protein. These various protein kinases are grouped into different families, which are further divided into subfamilies. Furthermore, these protein kinases are classified by sequence comparison of their respective catalytic domains, domain structure or by substrate specificities. Further distinctions can be drawn between tyrosine kinases and serine/threonine kinases (2). Protein kinase CK2, formerly termed casein kinase II, is a dual specific protein kinase, which phosphorylates either serine/threonine or tyrosine residues. Furthermore, in contrast to many other protein kinases, CK2 phosphorylates a plethora of different substrates and therefore this kinase participates in numerous different functions $(3,4)$. With the steadily increasing number of physiological substrates of $\mathrm{CK} 2$, it becomes more evident that CK2 has the potential to participate in nearly every cellular process. There are excellent reviews regarding the role of CK2 in cell proliferation and survival (5), cancer (6,7), apoptosis (8), angiogenesis (9), DNA-damage and repair (10), the ER-stress response (11), the regulation of carbohydrate metabolism (12) and in the nervous system (13). With regard to these various functions, the mechanism by which a single enzyme regulates these different activities remains to be elucidated. One answer is the ubiquitous distribution in eukaryotic cells from the cell nucleus to the plasma membrane (14), where CK2 meets different substrates and may be specifically activated or inactivated in one particular compartment. Furthermore, CK2 most often appears as a tetrameric complex consisting of two catalytic $\alpha$ - or $\alpha^{\prime}$ - and two non-catalytic $\beta$-subunits. The tetrameric holoenzyme may be composed of two CK2 2 , or two CK2 $\alpha^{\prime}$ or one CK $2 \alpha$ and one CK $2 \alpha^{\prime}$ subunit, and two non-catalytic $\beta$-subunits. The non-catalytic $\beta$-subunit is not an on/off regulator of the catalytic activities of the $\mathrm{CK} 2 \alpha$ or $\mathrm{CK} 2 \alpha^{\prime}$ subunits. It seems to regulate thermostability, substrate specificity and the ability to attach and penetrate the cell membrane (15-19). Furthermore, CK2 forms high-order oligomers depending on the ionic strength in the environment (20-24).

In addition, there is increasing evidence for functions of the CK2 subunits outside of the holoenzyme (25-29). The hypothesis that these observations point to an additional mode of regulation is supported by the identification of a number of cellular proteins, which regulate CK2 kinase activity (30). According to the large number of different substrates, as well as the various modes of regulation of the CK2 protein kinase activity, it follows that life without CK2 $\alpha$ and CK2 $\beta$ is impossible (31-33). There is a notable review article regarding the role of CK2 in development of various organisms (34); 
however, the present review attempts to focus on the role of CK2 in development and differentiation in vertebrates.

\section{CK2 during embryogenesis}

The first report on protein kinase CK2 in embryogenesis was published in 1986 when Schneider et al (35) demonstrated that CK2 activity increased on day 11 and reached a peak on day 12 of mouse embryonic development. These findings were confirmed for rat embryonic development (36) and similar results were reported for mRNA expression during chicken development (37). These early reports were followed by a study regarding the expression and distribution of CK2 in various tissues in mouse embryos at different stages (38). In the majority of cases the level of mRNA transcripts correlated well with the protein level of the two subunits, CK2 $\alpha$ and CK $2 \beta$. Only in skin was a marked difference between CK $2 \alpha$ and CK $2 \beta$ transcripts and protein levels detected late in embryogenesis. In addition, CK2 $2 \alpha^{\prime}$ is the predominantly expressed catalytic CK2 subunit in testis. CK2 $2 \alpha^{\prime}$ knock-out testes demonstrated extensive germ cell degenerative processes at all stages of spermatogenesis $(39,40)$ indicating a role for CK $2 \alpha^{\prime}$ in development and differentiation. CK $2 \alpha^{\prime}$ knock-out mice, however, are viable whereas a CK2 $\alpha$ knock-out is lethal during embryonal development (31). These results indicate that the two catalytic subunits cannot substitute each other, indicating individual roles in development and differentiation. When the $\alpha$-subunit of CK2 was knocked out in mice, embryos exhibited structural injuries in the heart and neural tube, and succumbed during embryogenesis $(31,32)$. A combination of the two knock-outs, $\alpha$ and $\alpha^{\prime}$, only resulted in offsprings when one of the catalytic subunits was sustained (25). However, all combinations demonstrate different and unique defects. Furthermore, these experiments have demonstrated that a combined loss of one CK2 $\alpha$ allele or the two CK $2 \alpha^{\prime}$ alleles leads to abnormalities in growth and development of the offspring. In particular CK2 $\alpha^{+/-} / \mathrm{CK} 2 \alpha^{1-1-}$ mice differ in weight, but not in size compared with their wild-type littermates. Furthermore, heterozygous knock-out mice were found to have $\sim 50 \%$ of the body fat when compared with mice of other genotypes.

Knock-out of CK2 $\beta$ in mice leads to lethality (33). The lack of CK2 $\beta$ causes a diminished cell proliferation and the development of the murine embryos ends at the blastocyste stage with the resorption of the embryo. CK2 $\beta^{-/}$blastocysts are not able to generate an inner cell mass (33). Notably, heterozygous CK2 $\beta\left(\mathrm{CK}_{2} \beta^{+-}\right)$knock-out mice do not exhibit an obvious phenotype (41) indicating a possible gene dosage effect. There was no correlation between CK2 $\beta$ levels in normal and CK $2 \beta^{+/}$ mice that were smaller in size or with gross abnormalities, but differently phosphorylated CK $2 \beta$ proteins were detected (41). The use of conditional CK2 $\beta$ knock-out mice revealed defects in proliferation and differentiation of embryonic neural stem cells (NSCs) (42). It was shown that CK2 $\beta$ was a positive regulator for the development of oligodendrocyte precursor cells. This regulation was achieved by binding of CK2 $\beta$ to, and phosphorylation of, the transcription factor, Olig-2. Thus, it has been concluded that CK2 $\beta$ may be essential in the development of the central nervous system. It was previously identified that a function of CK $2 \beta$ in the holoenzyme, and not a separate function of CK2 $\beta$, was required for stem cell homeostasis (43).

\section{CK2 and neuronal differentiation}

The high abundance of all CK2 subunits in brain suggests that CK2 may be important in neural differentiation (44). The disruption of CK2 $\beta$ in embryonic NSCs leads to a restricted proliferation and a weaker differentiation of oligodendrocytes (42), potentially by regulating the activity of the transcription factor Olig-2. Previously, Blanquet (13) suggested that CK2 may be involved in the neuronal cell development program. This suggestion was based on the observations that numerous different substrates of CK2 were involved in neuritogenesis, such as the microtubule-associated protein (MAP)-1B, MAP-1A and tau $(45,46)$. During neural cell differentiation, complexes between transcriptional corepressors of the Groucho/transducin-like enhancer of split (Gro/TLE) and various DNA binding proteins participate in the regulation of this process. One of the proteins within this complex, namely transcription factor, Hes-1, has been identified as a CK2 substrate (47). Inhibition of the enzyme activity of CK 2 reduces the chromatin-association. Hes-1 inhibits neuronal differentiation, whereas the associated Hes- 6 protein promotes neuronal differentiation. Hes- 6 inhibits the interaction of Hes-1 with Gro/TLE and it promotes the proteolytic degradation of Hes-1. In addition, Hes- 6 is a substrate for CK2 and its interaction with Hes-1 is regulated by CK2 phosphorylation (48). Finally, Gro/TLE has been identified as a substrate for CK2 (49). The CK2 phosphorylation of Gro/TLE occurs within a CCN motive, which is characterized by phosphorylation sites for cyclin-dependent kinase (cdk)1 (C) and CK2 (C) and a nuclear localization signal (N) (50). CK2 phosphorylation within this CCN motive regulates nuclear translocation for proteins, including Gro/TLE, and transcriptional repression (49). It was further demonstrated that phosphorylation of Gro/TLE by CK2 was required to inhibit the differentiation of cortical neural progenitor cells into neurons. Fibroblast growth factor-2, which enhances proliferation and neurogenesis of NSCs (51) interacts with CK2 via its regulatory $\beta$-subunit and stimulates the phosphorylation of nucleolin (52). cdk5 is another protein, which is implicated in the regulation of neuronal differentiation (53). Although there is a $60 \%$ sequence identity between cdk $1, \mathrm{cdk} 2$ and cdk5 (according to the Global Alignment Program of the National Center for Biotechnology Information; https://blast. ncbi.nlm.nih.gov/Blast.cgi), the latter is not primarily active as a cell cycle regulating enzyme. cdk5 exerts no enzymatic activity, and is activated by binding to the regulatory subunits p35 and p39, which are expressed in post-mitotic neurons. By pull-down experiments, size exclusion chromatography and co-immunoprecipitation the CK2 $\alpha$ subunit was found to be associated with p35 and cdk5 (54). This association is independent of kinase activity. Furthermore, CK2 $\alpha$ inhibits the kinase activity of cdk 5 by preventing the binding of cdk 5 to $\mathrm{p} 35$. This interaction appears to provide a protection mechanism, which supports cell viability in the nervous system.

Bone morphogenetic proteins (BMPs) restrict neural differentiation. Activation of the BMP-2 signalling pathway leads to increased levels of inhibitor of DNA binding 1, HLH protein, which negatively regulates mammalian achaete scute 
homolog-1 (Mash1)-dependent transcription in neurogenic precursor cells by sequestering E proteins away from Mash1 and by enhancing its degradation (55). Conversely, Mash1 is phosphorylated by protein kinase CK2 at serine 152 . This phosphorylation is triggered by its complex partner E47 and increases further heterodimer interaction, thus positively regulating neurogenesis.

N-methyl-D-aspartate receptors (NMDARs) belong to the class of ionotropic glutamate receptors, which are ubiquitously expressed in the nervous system (56). NMDARs are composed of NR1, NR2 A-D and NR3 A-B which form tetramers composed of two NR1 and two NR2 or NR3 subunits (57). CK2 phosphorylates NR2B (58), which drives the endocytosis of NR2B resulting in an increased expression of synaptic NR2A. This switch from NR2B to NR2A occurs at cortical synapsis during development (59).

\section{CK2 and adipogenic differentiation}

For more than 40 years the cellular and molecular mechanisms of adipocyte differentiation have been extensively investigated. The majority of these studies were performed with pre-adipocyte models, for example the mouse cell lines 3T3-L1, 3T3-F442A or C3H10T1/2. As adipocytes are derived from multipotent mesenchymal stem cells, there have also been attempts to analyse mechanisms of adipogenesis in this experimental system. A first indication for the role of CK2 during adipogenesis stems from a study by Sommercorn and Krebs (60) in 1987, which described an increase in CK2 kinase activity early after induction of differentiation. As differentiation progressed, the quantity of CK2 and kinase activity decreased to a level that was almost undetectable. This early observation was recently confirmed and extended for all three CK2 subunits and for CK2 kinase activity. Pharmacological inhibition of CK2 revealed that differentiation was abrogated when CK2 was inhibited at early time points after differentiation commenced (61). After day six of differentiation, inhibition of CK2 activity demonstrated no effect on the differentiation process. Very similar results were reported for the adipogenic differentiation of human mesenchymal stem cells (62). In this case it was, however, shown that mesenchymal stem cells respond differently to the type of inhibitor for the CK2 enzyme activity. For example, quinalizarin efficiently inhibited the differentiation process, whereas CX-4945 failed to inhibit differentiation. Furthermore, there was an asymmetric loss of CK $2 \alpha$ and $\mathrm{CK} 2 \beta$ subunits during the course of differentiation. CK2 inhibition by quinalizarin was accompanied by a loss of the nuclear localization of peroxisome proliferator-activated receptor (PPAR) $\gamma 2$ to a more cytoplasmic localization. As PPAR $\gamma 2$ is one of the key transcription factors for successful differentiation these data may indicate the method by which CK2 is implicated in the regulation of adipogenesis. In a recent study one of the members of the CCAAT-enhancer-binding proteins (C/EBP) family of transcription factors, namely $\mathrm{C} / \mathrm{EBP} \delta$ was identified as a substrate for CK2 (63). Co-expression of CK2 together with $\mathrm{C} / \mathrm{EBP} \delta$ enhanced the transcription factor activity of $\mathrm{C} / \mathrm{EBP} \delta$, and pharmacological inhibition of $\mathrm{CK} 2$ reduced the transcriptional activity of $\mathrm{C} / \mathrm{EBPS}$. Given that $\mathrm{C} / \mathrm{EBP} \delta$ is an upstream transcription factor of PPAR $\gamma 2$, reversible phosphorylation of this transcription factor appears to be an additional regulatory mode for $\mathrm{CK} 2$ during adipogenesis. The zinc finger protein (ZNF), ZNF638 is another transcription factor that has been identified as an early regulator of adipocyte differentiation. ZNF638 physically interacts and transcriptionally co-operates with $\mathrm{C} / \mathrm{EBP} \beta$ and $\mathrm{C} / \mathrm{EBP} \delta$ in the regulation of PPAR $\gamma(64)$. According to an in silico analysis (http://www.expasy.org/), ZNF638 should be a CK2 substrate.

\section{CK2 and myogenic differentiation}

Mesenchymal stem cells are also capable of myogenic differentiation. As with adipogenic differentiation of mesenchymal stem cells, myogenic differentiation is also controlled by various cytokines, growth factors, extracellular matrix molecules and transcription factors (65). One of these transcription factors is the paired box 3 ( $\mathrm{Pax} 3$ ) protein, which was found to be phosphorylated (66). Finally the kinase, which is responsible for this phosphorylation at serine 205, has been identified as CK2 (67). This CK2 phosphorylation has been found in proliferating, but not differentiated, primary myoblasts (66). The phosphorylation is part of a priming event where phosphorylation at serine 205 is a first event required for a subsequent phosphorylation at serine 201 by glycogen synthase kinase $3 \beta$. Serine 205 phosphorylation is a further requirement for the phosphorylation at serine 209, which is also by CK2. Serine 205 phosphorylation is associated with proliferation whereas serine 209 phosphorylation is more associated with myogenic differentiation (68). Notably, in mutated Pax3, which is typically associated with rhabdomyosarcoma, this phosphorylation is maintained and may be responsible for the proliferating properties of these types of tumour cell (68).

The myogenic regulatory factors (MRFs) are a subclass of transcription factors, which are characterized by a common helix-loop-helix (bHLH) motif. They interact with another bHLH protein from the E protein family. Two members of the MRF family, MyoD and MRF4, are phosphoproteins and have been identified as CK2 substrates (69). Using MRF4 and MyoD mutants, which are no longer phosphorylated by CK2, and CK2 overexpression resulted in elevated transcriptional activity and enhanced myogenic activity demonstrating that phosphorylation of MRF4 and MyoD by CK2 was not responsible for this activity (69). Rather, one of the E proteins, E47 was phosphorylated by CK2 and this phosphorylation inhibited its DNA binding activity. Furthermore, Johnson et al (69) suggested a model where the phosphorylation of E47 by CK2 may increase the pool of E proteins that bind to MRF proteins. These MRF/E heterodimers may then transactivate muscle gene expression.

Myogenic factor (Myf)-5 is a member of a family of muscle-specific transcription factors, which are important for myogenic cell determination and differentiation. Winter et al (70) reported that Myf-5 was phosphorylated at two serine residues, one in the N-terminal and another one in the C-terminal domain of the protein. The two CK2 phosphorylation sites are required for the transcriptional activity of Myf-5 (70). Thus, it has been suggested that the N-terminal CK2 phosphorylation site regulates nuclear translocation of Myf-5.

In response to injury or a disease, skeletal muscle cells are dependent on a stem cell population termed satellite cells 
in order to guarantee compensatory growth regeneration. Establishment of the satellite cell lineage is controlled by the paired-box transcription factor, Pax7. Loss of Pax7 results in a severe reduction of muscle regenerative capacity. It has been shown that Pax7 is subjected to caspase 3-directed proteolytic degradation (71). Caspase 3 is a member of the caspases, which are implicated in the proteolytic cascade of apoptosis regulation. By using a combination of bioinformatics, peptide arrays and peptide cleavage assays, and by comparing overlapping protein kinase phosphorylation sites with caspase recognition motifs, CK2 was identified as a global regulator of apoptosis (72). Pax7 was identified as a CK2 substrate and the CK2 phosphorylation site was identified to be overlapping with a caspase 3 consensus site (71). Furthermore, phosphorylation of Pax 7 by CK 2 prevents caspase 3 cleavage and promotes satellite cell self-renewal (71). Thus, these results clearly indicate that CK2 is involved in the differentiation process, as well as the life of muscle stem cells by limiting the self-renewal process.

\section{CK2 and osteogenic differentiation}

Throughout human life, bone is maintained in balance by the complex coordination of multiple types of bone marrow cell. Bone formation by osteoblasts and resorption of osteoclasts are tightly regulated processes. The imbalance between bone formation and resorption is responsible for various diseases. Osteoblasts regulate osteoclast activity through cell-to-cell contacts whereby the osteoblast surface receptor activator of nuclear factor $(\mathrm{NF})-\kappa \mathrm{B}$ ligand, receptor activator of nuclear factor $\kappa-\mathrm{B}$ ligand (RANKL) binds to its receptor of $N F-\kappa B$ RANK. Ikaros was originally described as a hematopoietic cell-specific zinc finger DNA binding protein, which is responsible for lymphocyte development (73). Ikaros was identified as a CK2 substrate (74). Subsequently, CK2 phosphorylation of Ikaros was demonstrated to be essential in the regulation of alkaline phosphatase, which is a major osteoplastic differentiation marker (75). Son et al (76) showed that pharmacological inhibition of CK2 by CX-4945 significantly inhibited the RANKL-induced osteoclast differentiation. Conversely, the BMP-2-induced osteoblast differentiation was enhanced (76). This CK2 inhibitor was originally described as an anti-cancer agent either alone or in combination with other therapeutic agents (77). CX-4945 inhibited the formation of RANKL-induced tartrate-resistant acid phosphatase (TRAP) in bone marrow-derived macrophages, which are induced to differentiate. Furthermore, CX-4945 inhibited the RANKL-mediated induction of nuclear factor of activated T-cells, cytoplasmic 1 and Akt phosphorylation (76).

BMPs are essential during embryonal development and regulate such diverse processes as neurogenesis, hematopoiesis and bone formation. In murine $\mathrm{C} 2 \mathrm{C} 12$ mesenchymal precursor cells BMPs bind to a BMP receptor (BR) and induce a SMAD- and p38-dependent signalling cascade. CK2 $\beta$ was identified as a binding factor for the BMP receptor type 1a (BRIa). BMP-2, which is a crucial factor for osteoblast differentiation, binds to BRIa and displaces CK $2 \beta$ from BRIa (78,79). Inhibition of this CK2 $\beta$-BRIa interaction led to an activation of the Smad signalling pathway. However, overexpression of CK $2 \beta$ or a dominant negative form of CK $2 \alpha$ increased BMP signalling and BRIa was phosphorylated by CK2 at three different sites. Peptides (length, 30 amino acids) were designed, which specifically blocked each site. These peptides included various amino acids flanking each phosphorylation site, which are important for the binding of CK2 to BRIa (80). Mutants of the CK2 phosphorylation sites abrogated the binding of CK2 to BRIa and induced osteogenesis or adipogenesis. Recently, it was shown that one of these peptides, namely CK2.1, induced chondrogenesis, but not osteogenesis in the mesenchymal stem cell line $\mathrm{C} 3 \mathrm{H} / \mathrm{T} 101 / 2$ (81). In addition, blocking the interaction of CK2 with BRIa induces differentiation of $\mathrm{C} 2 \mathrm{C} 12$ cells into osteoblasts and adipocytes. Notably, the peptides CK2.1 and CK2.3 appeared to signal through more specific signalling pathways than binding of BMP-2 to its receptor $(81,82)$. By using one of these blocking peptides it was shown that an injection of this peptide into the tail vein of mice resulted in increased bone mineral density (82). The differentiation into osteoblasts is regulated via SMAD/mechanistic target of rapamycin or mitogen-activated protein kinase kinase (MEK) signalling pathways, whereas differentiation into adipocytes is dependent on SMAD4, p38 and MEK signalling. Furthermore, administration of this peptide led to an induced phosphorylation of extracellular signal-regulated kinases (ERK), but not Smad in osteocytes and osteoblasts. Mice treated with this peptide exhibited a decreased osteoclast differentiation and osteoclast activity (82). This was consistent with a previous observation regarding the crucial role of BMP-2, the downstream targeting BRIa and CK2 in regulating osteogenesis (80). The mechanism of action of these peptides remains unknown. Whether these peptides prevent binding of CK2 to BRIa or binding and phosphorylation of BRIa requires further investigation. Previous studies demonstrated that blocking peptides could be used in vivo to increase bone growth, which indicated that peptides may be a novel therapeutic strategy for bone fracture (78-82). Furthermore, CK2 may serve as a target for treatment of bone fractures or for osteoporosis.

BMP-2 induced the expression of alkaline phosphatase, which is a marker for osteoblast differentiation (83) and this induction was enhanced following CK2 inhibition. In addition, the mRNA level for osteogenic BMP-4 was enhanced subsequent to CK2 inhibition with CX-4945. Analyzing the signalling pathway following CK2 inhibition indicated that CX-4945 enhanced BMP-2 induced phosphorylation of ERK1/2.

\section{CK2 in hematopoietic differentiation}

Ikaros is essential in thymocyte differentiation where it undergoes dephosphorylation (84). At least two amino acids have been shown to be dephosphorylated during thymocyte differentiation, which were previously phosphorylated by CK2 . These data indicated the role of CK2 and the phosphorylation of Ikaros during $\mathrm{T}$ cell differentiation $(85,86)$. Certain Ikaros phosphorylation sites, which are mediated by CK2, were identified within a typical PEST sequence, which function as a recognition motif for protein degradation. Whereas alanine mutants at the CK2 phosphorylation sites within the PEST sequence stabilized Ikaros (85). These data are consistent with earlier observations where an overexpression of CK $2 \alpha$ contributed to the development of $\mathrm{T}$ cell leukaemia and 
lymphoma (87-90). Notably, these results correlate well with impaired Ikaros functions $(73,91)$.

$\mathrm{CD}^{+}{ }^{+}$regulatory $\mathrm{T}$ cells $\left(\mathrm{T}_{\text {reg }}\right.$ cells $)$ are essential in the maintenance of peripheral tolerance. Recently, it was shown that the suppression of an allergic immune response by $\mathrm{T}$ helper type $2\left(\mathrm{~T}_{\mathrm{H}} 2\right)$ cells was dependent on CK2 (92). In a mouse model in which only $\mathrm{T}_{\text {reg }}$ cells lacked CK2 $\beta$, a marked increase in infiltration of immune cells into the lung, but not in other organs was observed. This result indicates that CK2 $\beta$ in particular may be implicated in a cell-type and tissue-specific uncontrolled $\mathrm{T}_{\mathrm{H}} 2$ response.

Recently it was demonstrated that CK2 is involved in the molecualr decision between $T_{H} 17$ and $T_{\text {reg }}$ cells (93). $T_{H} 17$ cells represent a subset of $\mathrm{T}$ cells, which are important for the immune response against bacteria and fungi, and $\mathrm{T}_{\text {reg }}$ cells are important for the maintenance of immune tolerance. The balance between these two subsets of $\mathrm{T}$ cells contributes to the severity of a disease. Ulges et al (93) reported that the inhibition of CK2 kinase activity, as well as downregulation of the expression of CK $2 \beta$ in $C D 4^{+} \mathrm{T}$ cells prevents the development of $\mathrm{T}_{\mathrm{H}} 17$ cells and promotes the generation of $\mathrm{T}_{\text {reg }}$ cells.

\section{Conclusion}

There is no differentiation or development without CK2. Organisms and organs cannot develop without CK2, and in recent years there have been increasing observations regarding the role of CK2 in embryogenesis and differentiation. Although, CK2 is indispensable for the development of organisms, in the majority of cases CK2 has a negative impact on the ongoing differentiation process of adult stem cells. However, its presence appears to be necessary for the early phase or the initiation of differentiation. It is tempting to speculate that CK2 is dispensable in the adult organism and in terminally differentiated cells, as inhibition of CK2 activity is not detrimental for the survival of normal cells (94). However, with high probability, cells of the stem cell niche, which are also present in different tissues and organs of the adult organism, have to be excluded from this statement. Thus, it is hypothesized that a lack of CK2 may inhibit the self-renewal and repair capacity of an organism.

\section{Acknowledgements}

The authors would like to thank Miss Lisa Schwind for input whilst preparing the manuscript.

\section{References}

1. Manning G, Whyte DB, Martinez R, Hunter T and Sudarsanam S: The protein kinase complement of the human genome. Science 298: 1912-1934, 2002.

2. Hunter T: A thousand and one protein kinases. Cell 50: 823-829, 1987.

3. Cozza G, Meggio F and Moro S: The dark side of protein kinase CK2 inhibition. Curr Med Chem 18: 2867-2884, 2011.

4. Wang G, Ahmad KA, Unger G, Slaton JW and Ahmed K: CK2 signaling in androgen-dependent and -independent prostate cancer. J Cell Biochem 99: 382-391, 2006.

5. St-Denis NA and Litchfield DW: Protein kinase CK2 in health and disease: From birth to death: the role of protein kinase CK2 in the regulation of cell proliferation and survival. Cell Mol Life Sci 66: 1817-1829, 2009.
6. Ruzzene M and Pinna LA: Addiction to protein kinase CK2: A common denominator of diverse cancer cells? Biochim Biophys Acta 1804: 499-504, 2010.

7. Trembley JH, Wang G, Unger G, Slaton J and Ahmed K: Protein kinase CK2 in health and disease: CK2: a key player in cancer biology. Cell Mol Life Sci 66: 1858-1867, 2009.

8. Ahmad KA, Wang G, Unger G, Slaton J and Ahmed K: Protein kinase CK2 - a key suppressor of apoptosis. Adv Enzyme Regul 48: 179-187, 2008.

9. Montenarh M: Protein kinase CK2 and angiogenesis. Adv Clin Exp Med 23: 153-158, 2014.

10. Montenarh M: Protein kinase CK2 in DNA damage and repair. Transl Cancer Res 5: 49-63, 2016.

11. Götz C and Montenarh M: Protein kinase CK2 in the ER stress response. Adv Biol Chem 3A: 1-5, 2013.

12. Al Quobaili F and Montenarh M: CK2 and the regulation of the carbohydrate metabolism. Metabolism 61: 1512-1517, 2012.

13. Blanquet PR: Casein kinase 2 as a potentially important enzyme in the nervous system. Prog Neurobiol 60: 211-246, 2000.

14. Faust $\mathrm{M}$ and Montenarh M: Subcellular localization of protein kinase CK2. A key to its function? Cell Tissue Res 301: 329-340, 2000.

15. Raaf J, Brunstein E, Issinger OG and Niefind K: The interaction of CK2alpha and CK2beta, the subunits of protein kinase CK2, requires CK2beta in a preformed conformation and is enthalpically driven. Protein Sci 17: 2180-2186, 2008.

16. Meggio F, Boldyreff BS, Marin O, Pinna LA and Issinger OG: CK2: Role of the b- subunit on the stability and specificity of the recombinant reconstituted holoenzyme. Eur J Biochem 204: 293-297, 1992.

17. Meggio F, Boldyreff B, Marin O, Marchiori F, Perich JW, Issinger OG and Pinna LA: The effect of polylysine on casein-kinase-2 activity is influenced by both the structure of the protein/peptide substrates and the subunit composition of the enzyme. Eur J Biochem 205: 939-945, 1992.

18. Boldyreff B, Meggio F, Pinna LA and Issinger OG: Casein kinase-2 structure-function relationship: Creation of a set of mutants of the beta subunit that variably surrogate the wildtype beta subunit function. Biochem Biophys Res Commun 188: 228-234, 1992.

19. Rodriguez FA, Contreras C, Bolanos-Garcia V and Allende JE: Protein kinase CK2 as an ectokinase: The role of the regulatory CK2beta subunit. Proc Natl Acad Sci USA 105: 5693-5698, 2008

20. Glover CV: A filamentous form of Drosophila casein kinase II. J Biol Chem 261: 14349-14354, 1986.

21. Mamrack MD: Stimulation of enzymatic activity in filament preparations of casein kinase II by polylysine, melittin, and spermine. Mol Cell Biochem 85: 147-157, 1989.

22. Valero E, De Bonis S, Filhol O, Wade RH, Langowski J, Chambaz EM and Cochet C: Quaternary structure of casein kinase 2. Characterization of multiple oligomeric states and relation with its catalytic activity. J Biol Chem 270: 8345-8352, 1995.

23. Valero E, Chambaz EM and Cochet C: Modulation of the protein kinase CK2 activity by a synthetic peptide corresponding to the $\mathrm{N}$-terminus of its beta regulatory subunit. Biochem Biophys Res Commun 232: 178-182, 1997.

24. Niefind $\mathrm{K}$ and Issinger OG: Primary and secondary interactions between CK2alpha and CK2beta lead to ring-like structures in the crystals of the CK2 holoenzyme. Mol Cell Biochem 274: 3-14, 2005 .

25. Landesman-Bollag E, Belkina A, Hovey B, Connors E, Cox C and Seldin DC: Developmental and growth defects in mice with combined deficiency of CK2 catalytic genes. Mol Cell Biochem 356: 227-231, 2011.

26. Filhol O, Nueda A, Martel V, Gerber-Scokaert D, Benitez MJ, Souchier C, Saoudi Y and Cochet C: Live-cell fluorescence imaging reveals the dynamics of protein kinase CK2 individual subunits. Mol Cell Biol 23: 975-987, 2003.

27. Filhol O, Martiel JL and Cochet C: Protein kinase CK2: A new view of an old molecular complex. EMBO Rep 5: 351-355, 2004.

28. Bibby AC and Litchfield DW: The multiple personalities of the regulatory subunit of protein kinase CK2: CK2 dependent and CK2 independent roles reveal a secret identity for CK2beta. Int J Biol Sci 1: 67-79, 2005.

29. Bolanos-Garcia VM, Fernandez-Recio J, Allende JE and Blundell TL: Identifying interaction motifs in CK2beta - a ubiquitous kinase regulatory subunit. Trends Biochem Sci 31: 654-661, 2006.

30. Montenarh M: Cellular regulators of protein kinase CK2. Cell Tissue Res 342: 139-146, 2010. 
31. Lou DY, Dominguez I, Toselli P, Landesman-Bollag E, O'Brien C and Seldin DC: The alpha catalytic subunit of protein kinase CK2 is required for mouse embryonic development. Mol Cell Biol 28: 131-139, 2008.

32. Dominguez I, Degano IR, Chea K, Cha J, Toselli $P$ and Seldin DC: CK $2 \alpha$ is essential for embryonic morphogenesis. Mol Cell Biochem 356: 209-216, 2011.

33. Buchou T, Vernet M, Blond O, Jensen HH, Pointu H, Olsen BB, Cochet $\mathrm{C}$, Issinger OG and Boldyreff $\mathrm{B}$ : Disruption of the regulatory beta subunit of protein kinase CK2 in mice leads to a cell-autonomous defect and early embryonic lethality. Mol Cell Biol 23: 908-915, 2003.

34. Alvarez LM, Revuelta-Cervantes J and Dominguez I: CK2 in embryonic development. in Protein kinase CK2. Pinna LA (ed) John Wiley \& Sons, Inc., Ames, Chichester, Oxford, pp129-168, 2013.

35. Schneider HR, Reichert GH and Issinger OG: Enhanced casein kinase II activity during mouse embryogenesis. Identification of a 110-kDa phosphoprotein as the major phosphorylation product in mouse embryos and Krebs II mouse ascites tumor cells. Eur J Biochem 161: 733-738, 1986.

36. Perez M, Grande J and Itarte E: Developmental changes in rat hepatic casein kinases 1 and 2. Eur J Biochem 170: 493-498, 1987.

37. Maridor G, Park W, Krek W and Nigg EA: Casein kinase II. cDNA sequences, developmental expression, and tissue distribution of mRNAs for alpha, alpha', and beta subunits of the chicken enzyme. J Biol Chem 266: 2362-2368, 1991

38. Mestres P, Boldyreff B, Ebensperger C, Hameister $\mathrm{H}$ and Issinger OG: Expression of casein kinase 2 during mouse embryogenesis. Acta Anat (Basel) 149: 13-20, 1994.

39. Wirkner U and Pyerin W: CK2alpha loci in the human genome: Structure and transcriptional activity. Mol Cell Biochem 191: 59-64, 1999.

40. Escalier D, Silvius D and Xu X: Spermatogenesis of mice lacking CK2alpha': Failure of germ cell survival and characteristic modifications of the spermatid nucleus. Mol Reprod Dev 66: 190-201, 2003.

41. Blond O, Jensen HH, Buchou T, Cochet C, Issinger OG and Boldyreff B: Knocking out the regulatory beta subunit of protein kinase CK2 in mice: Gene dosage effects in ES cells and embryos. Mol Cell Biochem 274: 31-37, 2005.

42. Huillard E, Ziercher L, Blond O, Wong M, Deloulme JC, Souchelnytskyi S, Baudier J, Cochet C and Buchou T: Disruption of CK2beta in embryonic neural stem cells compromises proliferation and oligodendrogenesis in the mouse telencephalon. $\mathrm{Mol}$ Cell Biol 30: 2737-2749, 2010.

43. Ziercher L, Filhol O, Laudet B, Prudent R, Cochet C and Buchou T: Structure-function analysis of the beta regulatory subunit of protein kinase CK2 by targeting embryonic stem cell. Mol Cell Biochem 356: 75-81, 2011.

44. Díaz-Nido J, Mizuno K, Nawa H and Marshak DR: Regulation of protein kinase CK2 isoform expression during rat brain development. Cell Mol Biol Res 40: 581-585, 1994.

45. Avila J, Ulloa L, González J, Moreno F and Díaz-Nido J: Phosphorylation of microtubule-associated proteins by protein kinase CK2 in neuritogenesis. Cell Mol Biol Res 40: 573-579, 1994.

46. Moreno FJ, Díaz-Nido J, Jiménez JS and Avila J: Distribution of CK2, its substrate MAP1B and phosphatases in neuronal cells. Mol Cell Biochem 191: 201-205, 1999.

47. Nuthall HN, Husain J, McLarren KW and Stifani S: Role for Hes1-induced phosphorylation in Groucho-mediated transcriptional repression. Mol Cell Biol 22: 389-399, 2002.

48. Gratton MO, Torban E, Jasmin SB, Theriault FM, German MS and Stifani S: Hes6 promotes cortical neurogenesis and inhibits Hes1 transcription repression activity by multiple mechanisms. Mol Cell Biol 23: 6922-6935, 2003.

49. Nuthall HN, Joachim K and Stifani S: Phosphorylation of serine 239 of Groucho/TLE1 by protein kinase CK2 is important for inhibition of neuronal differentiation. Mol Cell Biol 24: 8395-8407, 2004.

50. Jans DA, Xiao CY and Lam MH: Nuclear targeting signal recognition: A key control point in nuclear transport? BioEssays 22: 532-544, 2000.

51. Kuhn HG, Winkler J, Kempermann G, Thal LJ and Gage FH: Epidermal growth factor and fibroblast growth factor-2 have different effects on neural progenitors in the adult rat brain. J Neurosci 17: 5820-5829, 1997.

52. Bonnet H, Filhol O, Truchet I, Brethenou P, Cochet $C$, Amalric $F$ and Bouche G: Fibroblast growth factor-2 binds to the regulatory beta subunit of CK2 and directly stimulates CK2 activity toward nucleolin. J Biol Chem 271: 24781-24787, 1996.
53. Jessberger S, Gage FH, Eisch AJ and Lagace DC: Making a neuron: Cdk5 in embryonic and adult neurogenesis. Trends Neurosci 32: 575-582, 2009

54. Lim ACB, Hou Z, Goh CP and Qi RZ: Protein kinase CK2 is an inhibitor of the neuronal Cdk5 kinase. J Biol Chem 279: 46668-46673, 2004.

55. Viñals F, Reiriz J, Ambrosio S, Bartrons R, Rosa JL and Ventura F: BMP-2 decreases Mash1 stability by increasing Id1 expression. EMBO J 23: 3527-3537, 2004.

56. Karakas E, Regan MC and Furukawa H: Emerging structural insights into the function of ionotropic glutamate receptors. Trends Biochem Sci 40: 328-337, 2015.

57. Cull-Candy SG and Leszkiewicz DN: Role of distinct NMDA receptor subtypes at central synapses. Sci STKE 2004: re16-re2004, 2004.

58. Chung HJ, Huang YH, Lau LF and Huganir RL: Regulation of the NMDA receptor complex and trafficking by activity-dependent phosphorylation of the NR2B subunit PDZ ligand. J Neurosci 24: 10248-10259, 2004

59. Sanz-Clemente A, Matta JA, Isaac JT and Roche KW: Casein kinase 2 regulates the NR2 subunit composition of synaptic NMDA receptors. Neuron 67: 984-996, 2010.

60. Sommercorn J and Krebs EG: Induction of casein kinase II during differentiation of 3T3-L1 cells. J Biol Chem 262: 3839-3843, 1987

61. Wilhelm N, Kostelnik K, Götz C and Montenarh M: Protein kinase CK2 is implicated in early steps of the differentiation of pre-adipocytes into adipocytes. Mol Cell Biochem 365: 37-45, 2012.

62. Schwind L, Wilhelm N, Kartarius S, Montenarh M, Gorjup E and Götz C: Protein kinase CK2 is necessary for the adipogenic differentiation of human mesenchymal stem cells. Biochim Biophys Acta 1853 (10 Pt A): 2207-2216, 2015.

63. Schwind L, Zimmer AD, Götz C and Montenarh M: CK2 phosphorylation of $\mathrm{C} / \mathrm{EBP} \delta$ regulates its transcription factor activity. Int J Biochem Cell Biol 61: 81-89, 2015.

64. Meruvu S, Hugendubler L and Mueller E: Regulation of adipocyte differentiation by the zinc finger protein ZNF638. J Biol Chem 286: 26516-26523, 2011.

65. Almalki SG and Agrawal DK: Key transcription factors in the differentiation of mesenchymal stem cells. Differentiation 92: 41-51, 2016.

66. Miller PJ, Dietz KN and Hollenbach AD: Identification of serine 205 as a site of phosphorylation on Pax 3 in proliferating but not differentiating primary myoblasts. Protein Sci 17: 1979-1986, 2008.

67. Dietz KN, Miller PJ and Hollenbach AD: Phosphorylation of serine 205 by the protein kinase CK2 persists on Pax3-FOXO1, but not Pax3, throughout early myogenic differentiation. Biochemistry 48: 11786-11795, 2009.

68. Iyengar AS, Loupe JM, Miller PJ and Hollenbach AD: Identification of CK2 as the kinase that phosphorylates Pax3 at Ser209 in early myogenic differentiation. Biochem Biophys Res Commun 428: 24-30, 2012

69. Johnson SE, Wang X, Hardy S, Taparowsky EJ and Konieczny SF: Casein kinase II increases the transcriptional activities of MRF4 and MyoD independently of their direct phosphorylation. Mol Cell Biol 16: 1604-1613, 1996.

70. Winter B, Kautzner I, Issinger OG and Arnold HH: Two putative protein kinase CK2 phosphorylation sites are important for Myf-5 activity. Biol Chem 378: 1445-1456, 1997.

71. Dick SA, Chang NC, Dumont NA, Bell RA, Putinski C, Kawabe Y, Litchfield DW, Rudnicki MA and Megeney LA: Caspase 3 cleavage of Pax7 inhibits self-renewal of satellite cells. Proc Natl Acad Sci USA 112: E5246-E5252, 2015.

72. Turowec JP, Duncan JS, Gloor GB and Litchfield DW: Regulation of caspase pathways by protein kinase CK2: Identification of proteins with overlapping CK2 and caspase consensus motifs. Mol Cell Biochem 356: 159-167, 2011.

73. Kathrein KL, Lorenz R, Innes AM, Griffiths E and Winandy S: Ikaros induces quiescence and T-cell differentiation in a leukemia cell line. Mol Cell Biol 25: 1645-1654, 2005.

74. Gómez-del Arco P, Maki K and Georgopoulos K: Phosphorylation controls Ikaros's ability to negatively regulate the G(1)-S transition. Mol Cell Biol 24: 2797-2807, 2004.

75. Son E, Do H, Joo HM and Pyo S: Induction of alkaline phosphatase activity by L-ascorbic acid in human osteoblastic cells: A potential role for CK2 and Ikaros. Nutrition 23: 745-753, 2007.

76. Son YH, Moon SH and Kim J: The protein kinase 2 inhibitor CX-4945 regulates osteoclast and osteoblast differentiation in vitro. Mol Cells 36: 417-423, 2013. 
77. Siddiqui-Jain A, Drygin D, Streiner N, Chua P, Pierre F, O'Brien SE, Bliesath J, Omori M, Huser N, Ho C, et al: CX-4945, an orally bioavailable selective inhibitor of protein kinase CK2, inhibits prosurvival and angiogenic signaling and exhibits antitumor efficacy. Cancer Res 70: 10288-10298, 2010.

78. Bragdon B, Thinakaran S, Moseychuk O, King D, Young K, Litchfield DW, Petersen NO and Nohe A: Casein kinase 2 beta-subunit is a regulator of bone morphogenetic protein 2 signaling. Biophys J 99: 897-904, 2010.

79. Bragdon B, Thinakaran S, Moseychuk O, Gurski L, Bonor J, Price C, Wang L, Beamer WG and Nohe A: Casein kinase 2 regulates in vivo bone formation through its interaction with bone morphogenetic protein receptor type Ia. Bone 49: 944-954, 2011.

80. Moseychuk O, Akkiraju H, Dutta J, D'Angelo A, Bragdon B, Duncan RL and Nohe A: Inhibition of CK2 binding to BMPRIa induces $\mathrm{C} 2 \mathrm{C} 12$ differentiation into osteoblasts and adipocytes. J Cell Commun Signal 7: 265-278, 2013.

81. Akkiraju H, Bonor J and Nohe A: CK2.1, a novel peptide, induces articular cartilage formation in vivo. J Orthop Res: Jun 17, 2016 (Epub ahead of print).

82. Akkiraju H, Bonor J, Olli K, Bowen C, Bragdon B, Coombs H, Donahue LR, Duncan R and Nohe A: Systemic injection of CK2.3, a novel peptide acting downstream of bone morphogenetic protein receptor BMPRIa, leads to increased trabecular bone mass. J Orthop Res 33: 208-215, 2015.

83. Franceschi RT and Iyer BS: Relationship between collagen synthesis and expression of the osteoblast phenotype in MC3T3-E1 cells. J Bone Miner Res 7: 235-246, 1992.

84. Georgopoulos K, Winandy S and Avitahl N: The role of the Ikaros gene in lymphocyte development and homeostasis. Annu Rev Immunol 15: 155-176, 1997.

85. Dovat S, Song C, Payne KJ and Li Z: Ikaros, CK2 kinase, and the road to leukemia. Mol Cell Biochem 356: 201-207, 2011.
86. Song C, Li Z, Erbe AK, Savic A and Dovat S: Regulation of Ikaros function by casein kinase 2 and protein phosphatase 1 . World J Biol Chem 2: 126-131, 2011.

87. Channavajhala $P$ and Seldin DC: Functional interaction of protein kinase CK2 and c-Myc in lymphomagenesis. Oncogene 21: 5280-5288, 2002.

88. Kelliher MA, Seldin DC and Leder P: Tal-1 induces T cell acute lymphoblastic leukemia accelerated by casein kinase IIalpha. EMBO J 15: 5160-5166, 1996.

89. Landesman-Bollag E, Channavajhala PL, Cardiff RD and Seldin DC: p53 deficiency and misexpression of protein kinase CK2alpha collaborate in the development of thymic lymphomas in mice. Oncogene 16: 2965-2974, 1998.

90. Seldin DC and Leder P: Casein kinase II alpha transgene-induced murine lymphoma: Relation to theileriosis in cattle. Science 267: 894-897, 1995

91. Avitahl N, Winandy S, Friedrich C, Jones B, Ge Y and Georgopoulos K: Ikaros sets thresholds for T cell activation and regulates chromosome propagation. Immunity 10: 333-343, 1999.

92. Ulges A, Klein M, Reuter S, Gerlitzki B, Hoffmann M, Grebe N, Staudt V, Stergiou N, Bohn T, Brühl TJ, et al: Protein kinase CK2 enables regulatory $T$ cells to suppress excessive $T_{H} 2$ responses in vivo. Nat Immunol 16: 267-275, 2015

93. Ulges A, Witsch EJ, Pramanik G, Klein M, Birkner K, Bühler U, Wasser B, Luessi F, Stergiou N, Dietzen S, et al: Protein kinase CK2 governs the molecular decision between encephalitogenic $\mathrm{T}_{\mathrm{H}} 17$ cell and $\mathrm{T}_{\text {reg }}$ cell development. Proc Natl Acad Sci USA 113: 10145-10150, 2016

94. Intemann J, Saidu NEB, Schwind L and Montenarh M: ER stress signaling in ARPE-19 cells after inhibition of protein kinase CK2 by CX-4945. Cell Signal 26: 1567-1575, 2014. 